\title{
Changes in the Environment of Scholarly Publishing: An Introduction
}

\author{
Irving Louis Horowitz and Mary E. Curtis
}

$\mathrm{T}$ The articles in this special issue, revised versions of presentations at the Seventh Annual Top Management Roundtable of the Society for Scholarly Publishing, reflect the maturation of scholarly publishing. By "scholarly publishing" we mean the community of people who are as much at home in the world of scholarship as in publishing, librarianship, and allied fields. Now this may seem a commonplace statement; but we think not.

The "tradition" - or at least the inheritance-of this area of publishing has been to define the publisher as someone who produces books and journals of professional worth in areas that may range from astrophysics to literature. Yet scholars working in this area have been considered authors-people to be seen and read, but not full participants in the enterprise with viewpoints worth listening to and learning from at meetings.

This artificial dualism is fast coming to an end, spurred in part by the development of organizations such as the Society for Scholarly Publishing. SSP seeks to bring together the entire community of people engaged in scholarly publishing at events such as this, where ideas and information can be shared with mutual learning as the result. The "bottom line" of financial interests meets the "bottom line" of research, to the benefit of all. The handmaiden of this union has been the new technology, that world of computer information and data retrieval which has changed traditional publishing and opened up new avenues for cooperation between scholars and publishers. We have joined forces not as a volitional act of diplomacy, but as a necessary stage in the evolution of scholarly publishing as a unified concept.

The program for this annual event was designed to provide a forum for reflection about the present and future directions of scholarly publishing. Speakers were asked to address key changes in the environment external to the individual publisher, to help develop and extend evaluation of the major strategic issues, risks, and opportunities that await us. The theme of change encompasses a number of concerns. An early session concerned changes in competitive trends - the impact of consolidation, mergers, and acquisitions and their broad significance. Speakers also addressed the increasing internationalization of scholarly publishing, and the impact of changes in institu-

Irving Louis Horowitz is president of Transaction Publishers and Hannah Arendt Professor of Sociology and Political Science, Rutgers University, New Brunswick, NJ 08903.

Mary E. Curtis is senior vice president and publisher at Transaction Publishers, Rutgers University, New Brunswick, NJ 08903. 
tional budgets and buying patterns, changes in university environments, and overpublishing. We speculated about new participants in the traditional publishing environment and possible long-term scenarios. Robert Baensch, Fred Kobrak, and Paula Kaufman addressed these issues.

Another session focused on changes in the marketplace. Speakers were Kendrick Noble, Phyllis Steckler, and Adrian Higham. They analyzed the impact of demographic changes in the professions that use scholarly publications; changes in mediating organizations such as wholesalers, subscription agents, and bookstores, and their importance for scholarly publishers; and market opportunities for scholarly publishers outside the United States.

Still another session concerned changes among customers and authors, with William Lofquist, Beth Luey, and Marcel LaFollette. They examined the impact of change on the expectations of those who use scholarly publicationsand how publishers, librarians, and others are responding to these changes. Historical perspective was provided in discussion of previous technological change and its impact on the relationship between authors and publishers. And specific concerns about the integrity of peer review and secrecy were discussed in the context of changes in mutual expectations and mutual obligations.

Finally, we looked at new technological trends and developments and their impact on the scholarly publishing environment. Richard Johnson spoke about new product opportunities resulting from technological change, what has worked and what has not, and how publishers should go about deciding when and how to explore these areas. Sandra Paul spoke about the impact of new technology on how effectively publishers reach their markets with traditional products. They emphasized the movement of all participants in the community of scholarly publishing toward shared standards of technology and performance.

A senior management roundtable such as this is unique in certain ways. First of all, the speakers and listeners alike share a longstanding commitment to scholarly publishing. It is an occasion for exchange of information and ideas among people with a lifelong commitment and an extensive knowledge base in the area. It is our hope that this publication will be shared and internalized by the next generation of senior managers and by those who are now considering dedicating their lives and careers to this area.

Second, "management" signifies more than running enterprises or telling people what to do. In its pure form, sound management provides leadership in the creation of values and ideas that make possible, yes, a surplus of revenues over expenses, but also better conditions for professional interaction. Above all, it implies an intention to incorporate the discoveries and innovation taking place in the larger society and economy, making them a part of the publishing community. Innovation does not occur behind closed doors. It takes place when management is acutely attuned to the discoveries that are made in the larger environment and is firmly committed to participating in the resulting changes. Only fifty years ago authors submitted manu- 
scripts to publishers prepared with pen and ink. This sobering reminder should help us put into perspective the technological maelstrom in which we find ourselves, and help us remember the unique position of those of us in scholarly publishing as we experience and employ these developments.

The articles included in this issue emerged from a roundtable in which each speaker benefited from the scrutiny, discussion, and criticism of peers, all of which is reflected here. What one reads here are finished products; what we heard was work in progress. The roundtable format offered those present the opportunity to pursue lively discussion in formal and informal contexts, and made this a special event.

A final note: this meeting took place in Phoenix, Arizona. It is not only a delightful setting, but a vigorous environment that boasts a local scholarly publishing community - from the Oryx Press in Phoenix to the University of Arizona Press in Tucson. The fact that the editor of $B R Q$ is at Arizona State University in Tempe further exemplifies the diaspora of American scholarly publishing as we move toward a new century. The advantages of such ecological and geographical extensions are readily apparent in these articles, written by professionals from many parts of the scholarly publishing community. We can begin to appreciate the fruits of this diversity in this special issue. 